Relations industrielles

Industrial Relations

\title{
Travail et condition humaine. Semaine des intellectuels catholiques 1962. Centre catholique des intellectuels français, 61 rue Madame, Paris 6; Librairie Arthème Fayard, 18 rue du Saint-Gothard, Paris, 14. 1962, 284 pages.
}

\section{Gérard Dion}

Volume 18, numéro 2, avril 1963

URI : https://id.erudit.org/iderudit/1021447ar

DOI : https://doi.org/10.7202/1021447ar

Aller au sommaire du numéro

\section{Éditeur(s)}

Département des relations industrielles de l'Université Laval

ISSN

0034-379X (imprimé)

1703-8138 (numérique)

Découvrir la revue

Citer ce compte rendu

Dion, G. (1963). Compte rendu de [Travail et condition humaine. Semaine des intellectuels catholiques 1962. Centre catholique des intellectuels français, 61 rue Madame, Paris 6; Librairie Arthème Fayard, 18 rue du Saint-Gothard, Paris, 14. 1962, 284 pages.] Relations industrielles / Industrial Relations, 18(2), 288-288. https://doi.org/10.7202/1021447ar

Tous droits réservés ( Département des relations industrielles de l’Université Laval, 1963
Ce document est protégé par la loi sur le droit d'auteur. L'utilisation des services d'Érudit (y compris la reproduction) est assujettie à sa politique d'utilisation que vous pouvez consulter en ligne.

https://apropos.erudit.org/fr/usagers/politique-dutilisation/ 
Travail et condition humaine. Semaine des intellectuels datholiques 1962. Centre catholique des inkelleatuels français, 61 rue Madame, Paris 6; Librairie Arthème Fayard, 18 rue du Saint-Gothard, Paris, 14. 1962, 284 pages.

Le développement des sciences et des techniques ont grandement transformé les conditions de travail. Toute la civilisation dans laquelle nous vivons est profondément marquée par le travail. Mais qu'est-ce donc que le travail, quelle est sa place, son rôle, sa signification dans la vie de l'homme, dans la famille, dans l'économie, dans la société, dans l'évolution de l'univers?

Ce sont là des questions que l'on s'est toujours posées, mais auxquelles on n'attachait pas l'importance qu'elles ont acquises aujourd'hui.

Des penseurs catholiques ont réfléchi sur les différents aspects du travail. Philosophes, théologiens, économistes, socio- logues dont la compétence et la réputation sont bien établies dans tous les milieux d'expresion française ont été invités à apporter les lumières de leur discipline respectives. Successivement on a abordé les thèmes suivants: Recherches chrétiennes; hypothèses marxistes; l'avenir du travail est-il socialiste? Civilisation du loisir? travail et condition féminine; l'art et le travail humain; travail, création, contemplation.

Vingt-cing auteurs se sont partagé la tâche d'analyser l'une ou l'autre de ces questions. Tous ne sont pas d'accord. Il faut s'y attendre, mais leur perspective, leur échelle de valeur sont les mêmes. Leurs études sont aussi d'inégale importance. La plupart, cependant, sont vraiment remarquables. L'ensemble de ces travaux se place a un niveau nettement supérieur et contribue à faire de cet ouvrage un des meilleurs que nous connaissons pour comprendre le travail dans toutes ses dimensions.

Geraro Dion

\section{PUBLICATIONS RÉCENTES RECENT PUBLICATIONS}

\section{Généralités}

\& Managerial Authority in the Employment Relationship 》, by Stanley Young, Journal, Vol. 5. No. 3, December 1962, pp. 207-213.

\& Management in Perspective : The $\mathrm{Fa}$ culty Role in University Governance », by Dale Yoder, Journal, Vol. 5, No. 3, December 1962, pp. 222-229.

* Humaniser et christianiser les réalités de la vie ouvrière », par Père Faureau, Les Dossiers, 40è année, no 2, février le 15,1963 , pp. 113-130.

«Les rivages atlantiques de l'Europe \$, par A.P. L'Action Populaire, no 166, mars 1963, pp. 257-259.

\& Perspectives sur une théologie du travail », par J. Thomas, L'Action Populaire, no 166, mars 1963, pp. 260-272.
« Activité de l'Institut de formation du Congrès des syndicats britanniques dans le domaine de l'éducation \$, Revue Internationale du Travail, vol. LXXXVII, no 4, avril 1963, pp. 420-423.

* Création de l'Institut interaméricain des hautes études syndicales », Revue Internationale du Travail, vol. LXXXVII, no 2, février 1963, pp. 185-187.

«Activités du Mouvement syndical chrétien du Pérou en matière d'éducation ouvrière », Revue Internationale du Travail, vol. LXXXVII, no 2, février 1963, pp. 187-188.

« Hacia donde es errastrada la empressa privada », Por Edmundo Felix Belmonte, Revista Patronal, Num. 230, pp. 3-6.

《 Power, Pluralism and Local Politics \$, by Thomas J. Anton, Administrative Science Quarterly, Vol. 7, No. 4, March 1963, pp. 425-457. 